\title{
Cardioprotection by Cocoa Polyphenols and $\omega-3$ Fatty Acids: A Disease-Prevention Perspective on Aging-Associated Cardiovascular Risk
}

\author{
Sergio Davinelli, Graziamaria Corbi, Stefano Righetti, Barry Sears, ${ }^{3}$ Hector Hugo Olarte, \\ Davide Grassi, and Giovanni Scapagnini ${ }^{1}$ \\ ${ }^{1}$ Department of Medicine and Health Sciences "V. Tiberio", University of Molise, Campobasso, Italy. \\ ${ }^{2}$ Department of Cardiology, San Gerardo Hospital, Monza, Italy. \\ ${ }^{3}$ Inflammation Research Foundation, Peabody, Massachusetts, USA. \\ ${ }^{4}$ CasaLuker S.A., Bogotà D.C., Bogotà, Colombia. \\ ${ }^{5}$ Department of Life, Health and Environmental Sciences, University of L'Aquila, L'Aquila, Italy.
}

\begin{abstract}
Cardiovascular disease (CVD) remains the leading cause of death today. Many of the biochemical alterations associated with the pathophysiology of CVD can be modified by adequate intakes of bioactive nutrients through a correct diet or supplementation. Recently, there has been growing public and clinical interest in cocoa polyphenols (CPs) and omega-3 ( $\omega$-3) fatty acids. A plethora of nutritional intervention trials and experimental studies demonstrates that consumption of these bioactive food compounds is beneficial to promote cardiovascular health. The purpose of this review is to summarize the major cardioprotective effects of CPs and $\omega-3$ fatty acids, providing a scientific rationale for incorporating the combination of these molecules as a nutritional intervention in the prevention of CVD. Although several studies have shown the individual cardioprotective nature of these compounds, a combination treatment with CPs and $\omega-3$ fatty acids may be a promising approach to enhance the preventive value of these molecules and reduce cardiovascular risk factors associated with aging. Therefore, this article also reviews some of the key studies on the interaction between CPs and the metabolism of $\omega-3$ fatty acids.
\end{abstract}

\section{KEYWORDS: • cardiovascular disease $\bullet$ functional food $\bullet$ inflammation $\bullet$ nutrition $\bullet$ oxidative stress $\bullet$ prevention} - supplementation

\section{INTRODUCTION}

C ARDIOVASCULAR DISEASE (CVD) is the leading cause of death today. Across the world, CVD results in 1 in 3 deaths per year and more than half of the deaths related to CVD occurs in individuals aged $65-74$ years. ${ }^{1}$ The economic load amounts to almost $€ 170$ billion annually in Europe and over $\$ 190$ billion per year in the United States. ${ }^{2,3}$ Cardiovascular aging includes atherosclerosis, coronary artery disease, hypertension, heart failure, and atrial fibrillation. Aged hearts are characterized by reduced contractility, impaired diastolic function, and atrium dilatation. Morphological changes that result in cardiac aging include calcification and cholesterol-rich plaque formation, in addition to defective relaxation and endothelial dysfunction. These alterations of the heart associated with aging occur in both the vasculature

Manuscript received 7 January 2018. Revision accepted 16 March 2018.

Address correspondence to: Sergio Davinelli, PhD, Department of Medicine and Health Sciences "V. Tiberio", University of Molise, Via De Sanctis snc, Campobasso 86100, Italy, E-mail: sergio.davinelli@unimol.it

C) Sergio Davinelli et al., 2018; Published by Mary Ann Liebert, Inc. This Open Access article is distributed under the terms of the Creative Commons License (http:// creativecommons.org/licenses/by/4.0), which permits unrestricted use, distribution, and reproduction in any medium, provided the original work is properly cited. and the myocardium. ${ }^{4,5}$ Moreover, the key molecular and cellular mechanisms underlying cardiovascular aging involve oxidative stress, mitochondrial dysfunction, age-related lowgrade inflammation, increased apoptosis, cellular senescence, reduced bioavailability of nitric oxide (NO), impaired bioenergetic efficiency, age-related decline of autophagy, and activation of the renin-angiotensin-aldosterone system. ${ }^{6,7}$ The major risk factor for CVD is advancing age, however, healthy lifestyle and diet have the potential to reduce CVD risk. Research on dietary interventions typically focuses on reducing one or more traditional CVD risk factors such as systolic blood pressure (BP) and low-density lipoprotein (LDL) cholesterol. Moreover, several studies showed how identification of the active constituents of specific dietary patterns is crucial in the formulation of appropriate dietary guidelines. ${ }^{8,9}$

\section{HEALTH BENEFITS OF COCOA AND OMEGA-3 FATTY ACIDS}

Many of the biochemical alterations associated with the pathophysiology of CVD can be modified by adequate intakes of bioactive nutrients through a correct diet or supplementation. ${ }^{10-12}$ In this context, functional foods and dietary supplements may exert a positive effect on the prevention of CVD. There is a great number of bioactive compounds with a 
wide spectrum of biological properties affecting heart and cardiovascular system. Over the past 10 years, researchers have become increasingly interested in cocoa polyphenols (CPs) due to their potent antiradical properties. Recent nutritional intervention trials and molecular studies demonstrate that consumption of cocoa, particularly rich in flavanols, is beneficial to promote cardiovascular health. ${ }^{13}$ For example, flavanol-rich cocoa decreases the plasma level of $\mathrm{F}_{2}-$ isoprostanes, markers of lipid peroxidation, and therefore, increases total antioxidant activity ${ }^{14}$ Among the wide variety of functional foods, there is growing public and clinical interest in marine fish oil and its high content of long-chain (LC) omega-3 $(\omega-3)$ fatty acids. Several epidemiologic studies suggested a reduced risk of CVD associated with fish oil consumption. Dietary LC $\omega-3$ polyunsaturated fatty acids (PUFAs) have strong anti-inflammatory properties and their beneficial effects have been reported in pathologies and conditions associated with inflammation, including CVD. The LC $\omega-3$ fatty acids showed improvement in systolic and diastolic $\mathrm{BP}$ and reduced inflammation within the artery wall. These compounds can also decrease the incidence of heart attack and/or stroke. ${ }^{15}$ The molecular basis of $\omega$-3 fatty acid action was not established until recently. The $\omega-3$ PUFAs compete with the storage of arachidonic acid (AA), replacing it and blocking the production of proinflammatory eicosanoids. Indeed, the family of eicosanoids is synthesized from AA by the initial activities of either cyclooxygenases (isoforms COX1 or
COX2) or lipoxygenases (LOX) and downstream enzymatic reactions. There are several main classes of eicosanoids: prostaglandins (PG), thromboxanes (Tx), leukotrienes (LT), and lipoxins (Lx). The $\omega-3$ PUFAs displace AA in membrane phospholipids, reducing the production of AA-derived eicosanoids, while increasing those (resolvins and protectins) generated from $\omega$-3 PUFAs (Fig. 1). This altered eicosanoid profile might influence inflammation, thrombosis, and vascular function. ${ }^{16}$ In this article, we highlight that a feasible combination of CPs and LC $\omega-3$ fatty acids may positively influence detrimental processes underlying cardiovascular aging. To the best of our knowledge, a review focusing on these compounds and the possible synergistic effects of CPs and LC $\omega-3$ supplementation on cardiovascular aging has not been performed. Therefore, the purpose of this review is to summarize the major cardioprotective properties of CPs and LC $\omega-3$ fatty acids to highlight how their combined use may be a promising preventive approach in CVD. The benefits of a combination treatment with these two dietary compounds will be also discussed.

\section{SEARCH STRATEGY}

The following question guided this review: "Is the combination of CPs and LC $\omega-3$ fatty acids more effective in affecting cardiovascular system than CPs or LC $\omega-3$ fatty acids alone?" The literature search was carried out referring to

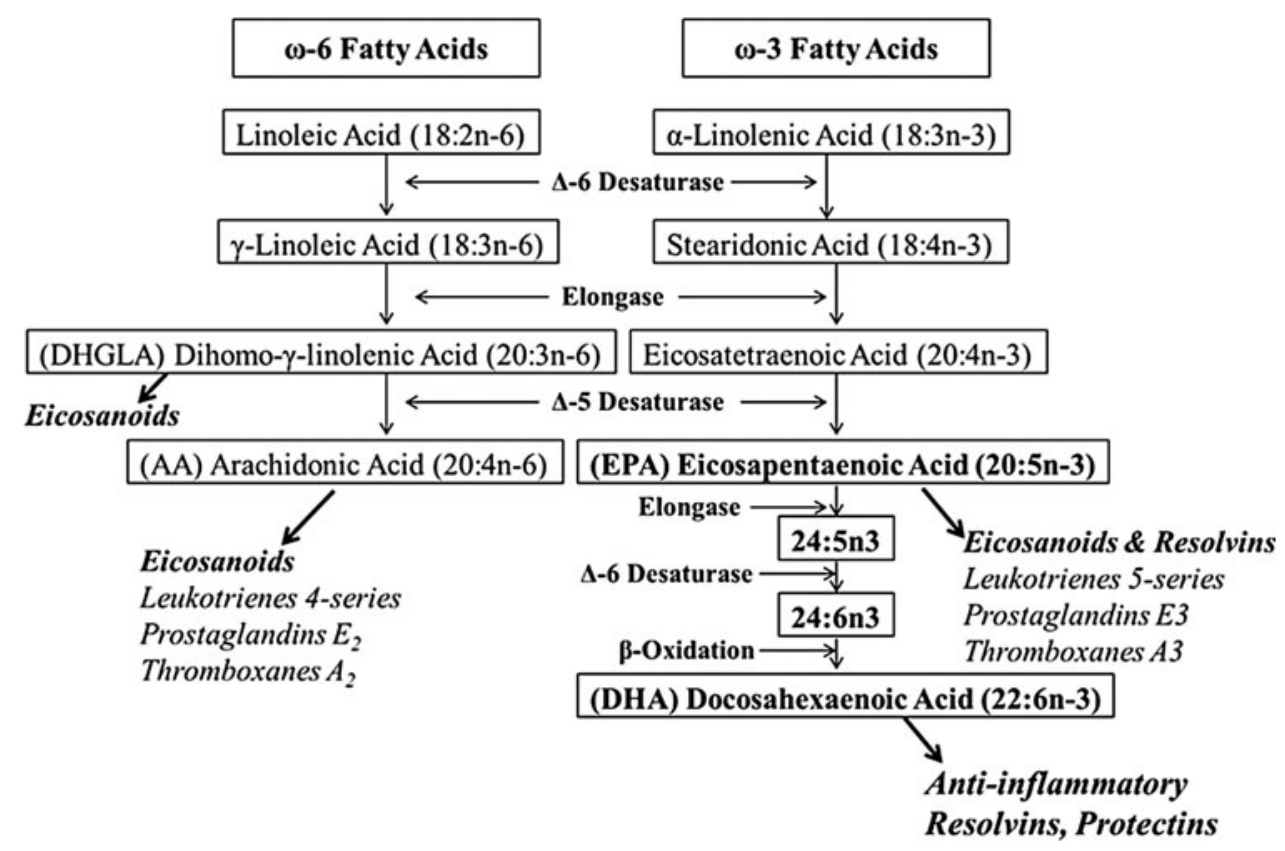

FIG. 1. PUFA and eicosanoid biosynthesis. ALA (18:3n-3) and LA (18:2n-6) are PUFAs obtained from the diet. Mammals convert LA and ALA to LC fatty acids using a series of desaturation and elongation reactions. Relevant intermediates to synthesize EPA (20:5n-3), DHA (22:6n-3), and AA (20:4n-6) include stearidonic acid, eicosatetraenoic acid, $\gamma$-linolenic acid, and DGLA (20:3n-6). AA and EPA are substrates for the synthesis of eicosanoid products such as PG and LT. EPA and DHA are also metabolized to resolvins and protectins, which are very potent antiinflammatory mediators. The products of $\omega-6$ fatty acids tend to promote inflammation, while the products of LC $\omega$-3 fatty acids have antiinflammatory properties. The LC $\omega-3$ fatty acids may reduce the risk of CVD by disrupting the biosynthesis of AA-derived inflammatory eicosanoids. AA, arachidonic acid; ALA, $\alpha$-linolenic acid; CVD, cardiovascular disease; DGLA, dihomo- $\gamma$-linolenic acid; DHA, docosahexaenoic acid; EPA, eicosapentaenoic acid; LA, linoleic acid; LC, long chain; LT, leukotrienes; PUFAs, polyunsaturated fatty acids; $\omega$-3, omega-3. 
PubMed, using predetermined keywords and a combination of Mesh terms. The search terms, combined with Boolean operator $\mathrm{AND} / \mathrm{OR}$, related to the aspects considered in this review were: (1) CVD: coronary artery, atherosclerosis, ischemic heart, ischemic, ischemia, cerebral stroke, cerebrovascular, CVD, cardioprotection, cardioprotective, cardiovascular prevention, cardiovascular aging; (2) Food/diet: cocoa, chocolate, dark chocolate, polyphenols, cocoa flavanols, cocoa flavonoids, cocoa catechins, polyunsaturated fatty acids, PUFA, PUFA metabolism, LC PUFA, $\omega-3$ PUFA, n-3 PUFA; $\omega-6$ PUFA, n-6 PUFA, $\omega-6 / \omega-3$ ratio, n-6/n-3 ratio. We then focused our attention on studies in English only, full length, performed on humans, in vitro or animal studies.

\section{CARDIOPROTECTIVE ACTIONS OF CPS}

Cocoa is recognized as a rich source of polyphenols. Total polyphenol content of the cocoa beans is about $6-8 \%$ by dry weight and black chocolate is considered one of the major source of antioxidants. ${ }^{17,18}$ The most predominant phenolic phytochemicals in cocoa are flavonoids, which include mainly flavonols, flavanols, flavanones, isoflavones, and nonflavonoids. ${ }^{18,19}$ Catechins, anthocyanidins/anthocyanins, flavonol glycosides, and procynanidins are the major polyphenolic compounds in cocoa. ${ }^{20}$ Table 1 provides a list of the main polyphenols found in cocoa. The molecular mechanisms of cocoa phytochemicals associated with their potential beneficial effects on human health have been reviewed extensively elsewhere. ${ }^{21}$ The studies on the cardiovascular effects of cocoa highlight that CPs mediate an increase of the bioavailability of $\mathrm{NO}$ in the endothelium and reverse endothelial dysfunction in CVD. NO from endothelium prevents leukocyte adhesion and migration, smooth muscle cell proliferation, platelet adhesion, and aggregation. CPs reduce vascular arginase activity in endothelial cells, which increases the levels of L-arginine used to synthesize NO by endothelial NO synthase (eNOS). Accordingly, increased NO bioavailability induced by CPs promotes a relaxation of vascular smooth muscle cells, leading to vasodilation. ${ }^{22}$ Besides their direct effects on eNOS activity, cocoa flavanols and procyanidins exert strong antioxidant effects. In general, bioactive compounds with antioxidant properties have been studied extensively to assess the effects on disease states such as CVD. For example, oxidation of LDL plays a crucial role in the formation of atherogenic plaques and numerous antioxidants prevent LDL oxidation and delay atherogenesis in animal models. However, a comprehensive Cochrane review of the impact of antioxidant supplements (administered singly or in various combinations) on healthy individuals (26 trials), or in people with one or more of a range of diseases (52 trials), including CVD (10 trials), found no overall reduction in all-cause mortality, irrespective of the combination of antioxidants used. ${ }^{23}$ Nevertheless, several studies have been performed to determine the role of CPs in lipid oxidation. Protection of LDL particles against oxidation by cocoa flavanols is a crucial mechanism accounting for the cocoa antioxidant property and to reduce atherosclerotic progression. ${ }^{24,25} \mathrm{Of}$ note, cocoa flavonoids interact with myeloperoxidase, an en-
Table 1. Major Cocoa Polyphenols

\begin{tabular}{|c|c|}
\hline Class & Compounds \\
\hline Flavanols & 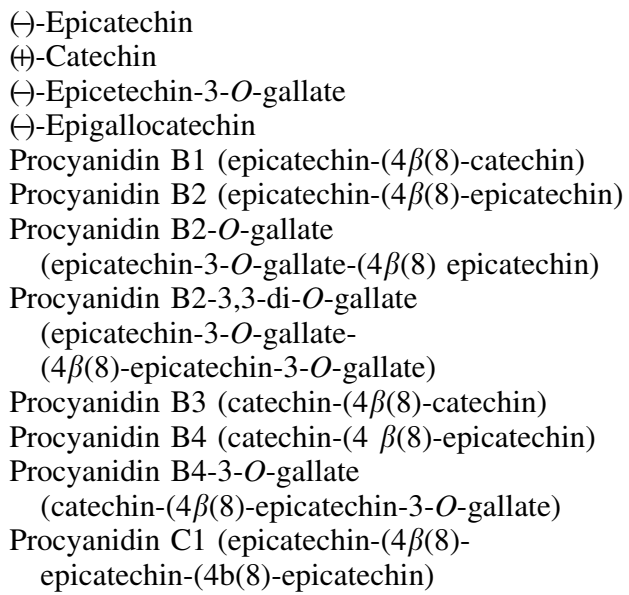 \\
\hline Flavonols & $\begin{array}{l}\text { Quercetin } \\
\text { Quercitin-3-O-arbinoside } \\
\text { Quercitin-3-O-galactoside } \\
\text { Isoquercitin }\end{array}$ \\
\hline Anthocyanins & $\begin{array}{l}\text { 3-alpha-L-Arabinosidyl cyanidins } \\
\text { 3-beta-D-Galactosidyl cyanidins }\end{array}$ \\
\hline Flavones & $\begin{array}{l}\text { Luteolin } \\
\text { Luteolin-7-O-hyperoside } \\
\text { Iso-orientin } \\
\text { Vitexin }\end{array}$ \\
\hline Flavanones & $\begin{array}{l}\text { Naringenin } \\
\text { Naringenin-7-O-glucoside }\end{array}$ \\
\hline Phenolic acids & $\begin{array}{l}\text { Chlorogenic acid } \\
\text { Vanillic acid } \\
\text { Coumaric acid } \\
\text { Phloretic acid } \\
\text { Caffeic acid } \\
\text { Ferulic acid } \\
\text { Phenylacetic acid } \\
\text { Syringic acid }\end{array}$ \\
\hline
\end{tabular}

zyme involved in peroxidation of LDL. The myeloperoxidasemediated peroxidation of LDL was blocked by CPs ${ }^{26}$ Other investigators observed that CPs have immunoregulatory effects and reduce the production of reactive oxygen species in activated leukocytes. ${ }^{27}$ Moreover, data from numerous studies suggest that cocoa flavanols can modify the inflammatory process and thus reduce cardiovascular risk. ${ }^{28}$ Long-term exposure to proinflammatory cytokines such as tumor necrosis factor alpha (TNF- $\alpha$ ) or interleukin 6 (IL-6) is detrimental to the myocardium and associated with chronic heart failure. ${ }^{29,30}$ Nuclear factor-kappa $\beta(\mathrm{NF}-\kappa \beta)$ is the major inducible transcription factors controlling the inflammatory response and the transcription of several proinflammatory cytokines. The modulation of the NF- $\kappa \beta$ signaling is important in the reduction of the inflammatory response and may represent a common pathway to all cocoa anti-inflammatory effects. Experimental evidence has demonstrated that cocoa epicatechin, catechin, and flavanols reduce NF- $\kappa \beta$ activation, thereby reducing production of proinflammatory cytokines and oxidative burst. ${ }^{31,32}$ 


\section{CARDIOVASCULAR BENEFITS OF COCOA FROM HUMAN STUDIES}

Epidemiological studies demonstrated that a diet rich in CPs reduces cardiovascular events in the general population. The Kuna Indians, a population living on the island off the Panama coast, have a diet characterized by high intake of cocoa and a lower BP compared to other Pan-American populations. The Kuna Indians have low incident of heart attack and stroke but after migration to an urban city they change their diet and this cardioprotection is lost. ${ }^{33}$ The Iowa Womens Health Study reported an inverse relationship between chocolate intake and mortality from coronary heart disease in postmenopausal women. ${ }^{34}$ The European Prospective Investigation into Cancer and Nutrition observed a lower rate of myocardial infarction and stroke, after 8 year of follow-up, in subjects who consumed $7.5 \mathrm{~g} /$ day of chocolate. ${ }^{35}$ Also the Stockholm Heart Epidemiology Program reported a lower cardiac mortality associated with higher chocolate intake in nondiabetic patients with previous myocardial infarction. ${ }^{36}$ Furthermore, several clinical trials have investigated the effects by which CPs potentially reduce CVD risk, improving lipid peroxidation, BP, inflammation, lipid metabolism, and glucose metabolism. ${ }^{37-40}$ Studies on the effects of CPs have shown that consumption of cocoa decreases LDL oxidation and lipid peroxidation biomarkers such as $\mathrm{F}_{2}$-isoprostane, among healthy subjects. ${ }^{14,41,42}$ Although the effect of cocoa products on lipid changes is equivocal, Grassi et al. reported that consumption of dark chocolate reduces serum LDL cholesterol concentrations in hypertensive subjects. ${ }^{43}$ In response to CPs consumption, it has also been shown an increase in plasma highdensity lipoprotein (HDL) cholesterol and a decrease in plasma triglyceride. ${ }^{41,44,45}$ Experimental data from rats showed a specific hypocholesterolemic effect of catechins. ${ }^{46}$ In addition, various studies have confirmed the role of flavonoids as antioxidants in biological systems. Flavonoids in chocolate have been shown to exert potent antioxidant effects in vitro assays under artificial oxidative stress and increase in antioxidant capacity as part of various chocolate feeding trials. ${ }^{47}$ Additionally, because lipid soluble flavonoids may intercalate into the membranes of lipoprotein particles, flavonoids may reduce lipid peroxidation of biological membranes. ${ }^{46,47}$ Nevertheless, a meta-analysis including 102 trials on HDL outcomes, and 92 on LDL outcomes, reported that chocolate, cocoa, and flavonoids consumption had no effect on LDL concentrations. ${ }^{37}$ Therefore, even though studies in both rats and humans reported that cocoa/chocolate consumption and intake of polyphenols suppressed serum LDL cholesterol concentrations and susceptibility of LDL to oxidation and increased HDL cholesterol levels, most of the studies showed a neutral effect on lipid profile. Cocoa and chocolate contain a high level of fats. Indeed, cocoa butter derived from cocoa plants and predominantly found in dark chocolate contains an average of $33 \%$ of oleic acid (cis-18:1 monounsaturated), $25 \%$ of palmitic acid (16:0 saturated), and $33 \%$ of stearic acid (18:0 saturated). ${ }^{48}$ In particular, several studies have suggested that stearic acid may be noncholesterolemic. ${ }^{48,49}$ A meta-analysis of 60 controlled feeding trials concludes that stearic acid neither lowers HDL, nor increases LDL or total cholesterol. ${ }^{50}$ This study also suggests that per $1 \%$ energy isocaloric replacement of stearic acid for carbohydrates, stearic acid ingestion significantly lower serum triglycerides by $17.0 \mathrm{nmol} / \mathrm{L}$. A more recent meta-analysis, aiming to evaluate the cardiometabolic effects of cocoa flavonoids (cocoa flavanols ranged from 166 to $2110 \mathrm{mg} / \mathrm{d}$, and intervention duration ranged from 2 to 52 weeks), showed that cocoa flavanol intake significantly improved insulin sensitivity and lipid profile. ${ }^{51}$ Furthermore, results from intervention studies reported that the intake of dark chocolate was associated with decreased systolic BP in healthy subjects, and this effect has also been observed in hypertensive subjects and glucose intolerant hypertensive patients. ${ }^{52,53}$ Recently, by applying the Framingham Risk Score, the Flaviola Health Study reported that cocoa flavanols improve endothelial function. In healthy individuals, regular cocoa flavanols intake improved cardiovascular biomarkers, demonstrating that dietary flavanols have the potential to maintain cardiovascular health even in lowrisk subjects. ${ }^{54}$ Cocoa flavanols have also a strong antiinflammatory properties in vitro but recent human studies reported a modest support to the anti-inflammatory effect of cocoa ${ }^{55}$ However, even though little clinical evidence exists that consumption of CPs may reduce inflammation, a randomized clinical trial with proanthocyanidine-rich cocoa powder demonstrated a reduction in plasma markers of inflammation in adults with high CVD risk. ${ }^{56}$ Some studies suggest that cocoa flavonoids may inhibit platelet aggregation by downregulating cellular eicosanoid synthesis. ${ }^{57-59}$ Eicosanoids are lipidic products involved in the regulation of the vascular tone and recruitment of immune cells into the vascular wall. In particular, eicosanoids such as PGE2, TxA2, and LT4 are derivatives of the AA and mediators involved in the inflammatory response. Despite the interest and the crucial role that CPs may exert as inhibitors of platelet aggregation, there is no a comprehensive study investigating the relationship between $\mathrm{CPs}$, inhibition of platelet aggregation, and downregulation of eicosanoid synthesis. Therefore, to clarify the antiplatelet action of CPs more studies are needed.

\section{CONSUMPTION OF LC $\omega$-3 FATTY ACIDS AND CARDIOVASCULAR PREVENTION}

The growing interest LC $\omega-3$ (or n-3) fatty acids was triggered by epidemiologic studies conducted with Greenland Eskimos. ${ }^{60}$ LC PUFAs of the $\omega-3$ series are essential dietary compounds because mammals cannot synthesize them. Of note, within the family of PUFAs there is also a different group belonging to the $\omega-6$ series. LC PUFAs can only be synthesized by mammals from the $\mathrm{C} 18$ precursors of each PUFA family, namely LC $\omega-6$ fatty acids from linoleic acid (LA, C18:2n-6) and LC $\omega$-3 fatty acids from $\alpha$-linolenic acid (ALA, C18:3n-3). The LC $\omega-3$ PUFAs influence multiple relevant molecular pathways associated with important 
and diverse roles in cellular and organelle membrane structure and function, tissue metabolism, and genetic regulation. Incorporation of $\omega-3$ PUFAs into cellular and organelle membranes influences membrane fluidity of lipid rafts that modulate protein function and signaling events. For example, ion channels such as sodium $\left(\mathrm{Na}^{+}\right)$, L-type calcium $\left(\mathrm{Ca}^{2+}\right)$, and $\mathrm{Na}^{+}-\mathrm{Ca}^{2+}$ exchangers can be modulated by $\omega-3$ PUFAs incorporation into lipid membranes. Moreover, $\omega-3$ PUFAs are natural ligands of many key nuclear receptors in multiple tissues, and also alter function of several transcription factors. ${ }^{61}$ This molecular regulation contributes to observed effects of $\omega$-3 PUFAs on lipid metabolism and inflammatory pathways. An adequate intake of LC $\omega-3$ fatty acids, specifically eicosapentaenoic (EPA, 20:5n-3) and docosahexaenoic (DHA, 22:6n-3) acids has been associated with lower incidence of CVD. ${ }^{62}$ Moreover, LC $\omega$-3 PUFAs EPA and DHA are metabolized to resolvins and protectins, which are very potent anti-inflammatory mediators in cellular and animal model systems (Fig. 1). Although recent clinical trials have failed to demonstrate a beneficial effect of LC $\omega-3$ supplementation on CVD, suggesting that fish is the advisable source of LC $\omega-3$ PUFAs, many studies including clinical trials and meta-analysis have concluded that consumption of fish, fish oils, or individual LC $\omega$-3 fatty acids is an effective dietary strategy to reduce CVD morbidity, mortality, and risk factors. ${ }^{63-68}$ Recently, the PREDIMED trial reported that in participants without previous CVD and high fish consumption, dietary ALA, supplied mainly by walnuts and olive oil, relates inversely to all-cause mortality, whereas protection from cardiac mortality is limited to fish-derived LC $\omega-3$ PUFAs. ${ }^{69}$ However, LC $\omega$-3 PUFAs have been shown to improve a number of cardiac parameters such as BP, heart rate, and endothelial function. ${ }^{70-73}$ The cardioprotective effects of LC $\omega$-3 PUFAs also include platelet aggregation inhibition, reduction of triglyceride levels, arrhythmia prevention, vascular relaxation improvement, anti-inflammatory responses, enhancement of plaque stability, and antiatherosclerotic effects. ${ }^{74-76}$ In particular, the greatest effect of LC $\omega-3$ fatty acids appears to be on triglycerides and is mainly due to a reduction in hepatic very-LDL-cholesterol synthesis. The mechanisms include increased fatty acid $\beta$-oxidation, increased hepatic synthesis of phospholipids instead of triglycerides, altered enzymatic activity for triglyceride assembly in the liver, and reduced fatty acid availability for triglyceride synthesis as a result of decreased de novo lipogenesis. ${ }^{74}$ To date, evidence supports that an adequate intake of LC $\omega-3$ PUFAs, either from fatty fish or from supplements, if continued for decades may contribute to reduce the risk for CVD. ${ }^{63}$

\section{THE IMPORTANCE OF $\omega$-6/ $\omega$-3 FATTY ACID RATIO IN CARDIOVASCULAR INFLAMMATION}

In the diet of our ancestors, the ratio of $\omega-6$ to $\omega-3$ fatty acids was 1 to 2/1 with higher levels of EPA, DHA, and AA. ${ }^{77}$ One of the most important consequences of the consumption of EPA and AA is to be included in plasma membrane phospholipids, particularly of platelets, erythrocytes, neutrophils, and monocytes. Today, the Western diet provides an $\omega-6$ to $\omega-3$ ratio of around $16: 1$, indicating a depletion of $\omega$-3 fatty acids. ${ }^{78}$ A balanced $\omega-6$ to $\omega$-3 PUFAs ratio may have a protective effect on age-related diseases, including CVD. Several studies have been conducted to determine the importance of the dietary $\omega-6 / \omega-3$ fatty acids ratio, rather than the level of individual PUFAs, in CVD prevention. ${ }^{79}$ Moreover, there is a metabolic competition between $\omega-6$ and $\omega-3$ since C18 precursor enzymes compete on the same enzymes for elongation and desaturation. It is noteworthy that $\omega-6$ and $\omega-3$ exert opposite physiological function, therefore an imbalance in $\omega-6 / \omega-3$ ratio may result in altered gene expression and disequilibrium in cell membrane composition and fluidity. ${ }^{80}$ The $\omega-6$ and $\omega-3$ fatty acids regulate and interact with multiple transcription factors and nuclear receptors such as peroxisome proliferator-activated receptors (PPARs), NF- $\kappa \beta$, and sterol regulatory element binding protein (SREBP), all of which influence inflammatory responses and lipid metabolism. ${ }^{81}$ The anti-inflammatory actions of eicosanoids from LC $\omega-3$ PUFAs are crucial to induce cardioprotective effects. Eicosanoids produced from C20 fatty acids are less inflammatory than their AA-derived eicosanoid counterparts and serve as vasodilators and inhibitors of platelet aggregation. ${ }^{82}$ The LC $\omega-3$ PUFAs can reduce the production of AA-derived eicosanoids by competing with AA. Therefore, high intake of dietary $\omega-6$ PUFAs increases the synthesis of proinflammatory eicosanoids derived from AA, and inhibits the synthesis of anti-inflammatory eicosanoids from EPA. ${ }^{79}$ Long-term production of proinflammatory eicosanoids from AA and high $\omega-6$ PUFAs dietary intakes may increase the risk of heart disease and contribute to the development of CVD. In contrast, a higher consumption of LC $\omega-3$ PUFAs in the diet results to have a favorable effect on $\omega-6 / \omega-3$ ratio and promote anti-inflammatory properties through the reduction of proinflammatory eicosanoid synthesis from monocytes, neutrophils, eosinophils, platelets, and endothelial cells. ${ }^{83-86}$

\section{CPS AND REDUCTION OF $\omega-6 / \omega-3$ FATTY ACID RATIO: POTENTIAL IMPLICATIONS ON CARDIOVASCULAR HEALTH}

The crucial role of $\omega-3$ PUFAs in the diet is evident, and the need to return to a more physiologic $\omega-6$ to $\omega-3$ ratio of $2: 1$ rather than the ratio of $16: 1$ provided by current Western diets. Experimental studies have provided evidence that dietary supplementation of LC $\omega-3$ PUFAs modifies inflammatory and immune reactions, suggesting LC $\omega-3$ PUFAs as potential therapeutic agents for inflammatory diseases. ${ }^{87}$ The metabolism of eicosanoids represents a novel target for the prevention or treatment of inflammation in CVD. ${ }^{88,89}$ The eicosanoid family includes derivatives of C20 PUFAs, mainly AA. This $\omega-6$ fatty acid is released from the phospholipids through the activity of phospholipase A2 (PLA2) enzymes, which are stimulated by inflammatory signals. Then, AA acts as a substrate for COX and LOX. COX 
enzymes lead to PGE2 and TxA2, LOX enzymes to LT4. Eicosanoids are recognized as crucial mediators of both physiological and pathophysiological responses of the microcirculation and also as key regulators of inflammation. These molecules play a crucial role on vascular permeability and tone and in the recruitment of various inflammatory cells from the circulation into tissues. It is important to highlight again that the conversion of ALA to EPA is in competition with the conversion of LA to AA, since the same enzymes are involved (Fig. 1). The $\Delta-6$ desaturase reaction is rate limiting in this pathway. Although the optimal substrate for $\Delta-6$ desaturase is ALA, LA is prevalent in human diets than ALA; therefore, metabolism of $\omega-6$ fatty acids is largely preferred. The $\omega-6$-PUFA AA is the primary source of fatty acids and elevated tissue levels of AA have been associated with inflammatory disease states, including obesity and CVD. ${ }^{90,91}$ However, LC $\omega$-3 fatty acids EPA and DHA inhibit AA metabolism, and EPA induces eicosanoid mediators such as PGE3, TxA3, and LT5 that may block the activity of those derived from AA. ${ }^{92}$ The antiinflammatory properties of LC $\omega-3$ PUFAs, especially EPA, are due to competition with AA as substrate for COX and 5lipoxygenase (5-LOX). To date, there are substantial data that EPA and DHA are able to inhibit several aspects of inflammation such as production of eicosanoids like PGE2 and LT 4 from the $\omega-6$ fatty acid AA. To improve the ratio of $\omega-6$ to $\omega-3$ PUFAs and reduce the production of proinflammatory eicosanoids, it is necessary to decrease the intake of $\omega-6$ PUFAs from vegetable oils and increase the intake of LC $\omega-3$ PUFAs by using oil fish and fish oil supplements. ${ }^{93}$ Interestingly, consumption of polyphenols from red wine has been associated with increased levels of EPA and DHA in patients with heart disease, a phenomenon referred to as a "fish-like" effect. ${ }^{94}$ In this context, although little research has been done to support the role of CPs in modulating eicosanoid metabolism, in vitro studies have shown that CPs are potent inhibitors of eicosanoid-generating enzymes, and can suppress the production of inflammatory eicosanoid metabolites. ${ }^{95,96}$ Although the effect of CPs on the AA metabolism remains to be completely defined, $\mathrm{Gu}$ et al. found that cocoa-supplemented mice had 33\% lower levels of AA compared with high-fat diet-fed mice. Furthermore, cocoa treatment also reduced availability of substrates for the synthesis of eicosanoids, particularly the protein levels of PLA2 and (COX-2). ${ }^{97}$ An imbalance in PGE2/TxA2 production has been linked to CVD and a shortterm investigation reported that chocolate procyanidins and cocoa flavanols decrease the ratio of PGE2/LT4 and PGE2/ TxA2 in humans, supporting the hypothesis that cocoaderived flavonoids can favorably alter eicosanoid synthesis in humans. ${ }^{98,99}$ From these data, it is possible to support the concept that CPs can modulate eicosanoid profiles and possibly reduce the detrimental effects of elevated intakes of $\omega-6$ fatty acids at the level of LA and AA. Moreover, a combination treatment with CPs and LC $\omega-3$ fatty acids may be a novel and effective rationale for future studies investigating the protective role of CPs and PUFAs. This rationale, depicted in Figure 2, provides a biochemical and clinical framework for pursuing clinical trials evaluating this combination as a nutritional approach to prevent CVD. Furthermore, it also reasonable to speculate that the combined effects of CPs and $\omega$-3 PUFAs may decrease the attenuation of endogenous protective mechanisms associated with the aged heart. A hypothesis regarding the effect of polyphenols on LC $\omega-3$ PUFAs metabolism is that they may accelerate the synthesis of EPA and DHA from their precursor ALA. Whether polyphenols influence $\Delta-6$ and $\Delta-5$ desaturases requires further studies, however, some classes of polyphenols have been linked at least partly to a PPAR $\alpha$ dependent mechanism that interferes with the PUFA elongation-desaturation pathway. ${ }^{100-102}$ Although the exact mechanisms involved in the interactions between polyphenols

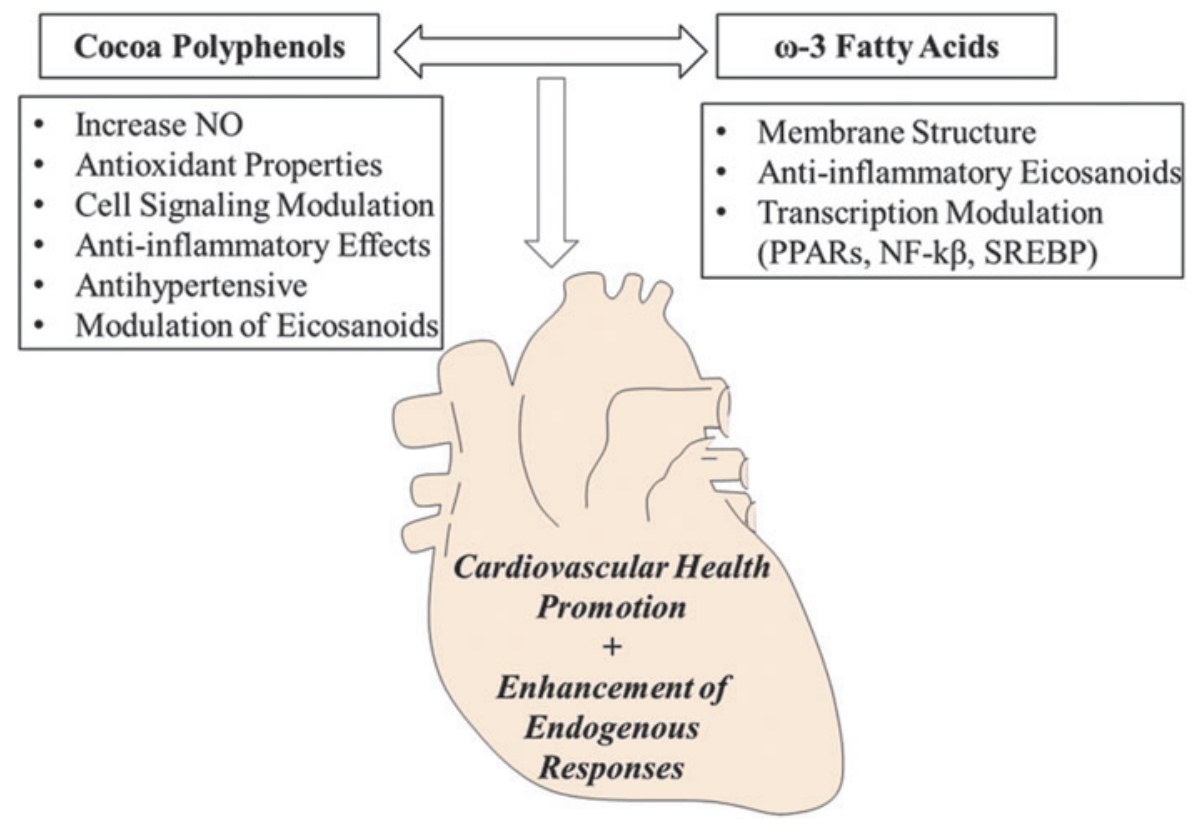

FIG. 2. Proposed nutritional strategy to reduce cardiovascular risk factors. This model links the combined use of CPs and $\omega-3$ fatty acids to cardiovascular health promotion. The figure represents a summary of the mechanisms that could potentially contribute to prevent or reduce the onset of age-related cardiovascular events and enhance cardioprotective responses. CPs, cocoa polyphenols. 
and PUFAs are not yet understood, recent data show that dietary flavonoids interact with the metabolism of LC $\omega-3$ PUFAs and increase blood EPA and DHA levels. ${ }^{103}$

\section{CONCLUSIONS}

Nutritional strategies for enhancing cardioprotection and reducing CVD risk will continue to be an important area of research. For instance, the ongoing Cocoa Supplement and Multivitamin Outcomes Study (COSMOS), which aims to determine the efficacy of a flavanol-rich cocoa using a 5-year randomized trial among 18,000 healthy men and women, may provide definitive evidence on the health benefits of cocoa on cardiovascular outcomes. ${ }^{104}$ Based on the existing literature discussed here, it is evident that CPs and LC $\omega-3$ PUFAs play crucial roles in the prevention of CVD. Many studies have shown the individual cardioprotective nature of these compounds, however, more efforts should be directed to understand whether a synergistic combination of CPs and LC $\omega$-3 PUFAs is more beneficial for CVD prevention. Despite the paucity of studies assessing the synergistic benefits of CPs and LC $\omega-3$ PUFAs on CVD, there is a growing body of evidence that can serve as a translational platform to design future human studies and address questions behind the fascinating outcomes of a combined approach using CPs and LC $\omega$-3 fatty acids. ${ }^{105-110}$ There are interesting preliminary results in rodent studies that encourage further work in this field and which hold promise for utilizing a combined use of CPs and LC $\omega-3$ fatty acids as a preventive tool in CVD. Although clinical/translational evidence already supports nutraceutical compounds for healthy aging, alternative strategies with combined actions of food bioactive compounds have the potential to enhance cardioprotection and cardiovascular health in older adults for whom a single compound may be not enough. Clearly, more work is needed to provide novel insights into the mechanisms by which CPs and LC $\omega$-3 fatty acids synergize to prevent and/or reduce cardiovascular risk factors. However, the co-administration of these agents may be a possible nutraceutical strategy for a number of disorders that affect the heart or blood vessels.

\section{ACKNOWLEDGMENT}

This was work partially supported by Equipe Enervit s.r.l. (Milano, Italy) research grant.

\section{AUTHOR DISCLOSURE STATEMENT}

No competing financial interests exist.

\section{REFERENCES}

1. Nichols M, Townsend N, Scarborough P, Rayner M: Cardiovascular disease in Europe 2014: Epidemiological update. Eur Heart J 2014;35:2929-2933.

2. Leal J, Luengo-Fernández R, Gray A, Petersen S, Rayner M: Economic burden of cardiovascular diseases in the enlarged European Union. Eur Heart J 2006;27:1610-1619.
3. Go AS, Mozaffarian D, Roger VL, Benjamin EJ, Berry JD, Blaha MJ, Dai S, Ford ES, Fox CS, Franco S, Fullerton HJ, Gillespie C, Hailpern SM, Heit JA, Howard VJ, Huffman MD, Judd SE, Kissela BM, Kittner SJ, Lackland DT, Lichtman JH, Lisabeth LD, Mackey RH, Magid DJ, Marcus GM, Marelli A, Matchar DB, McGuire DK, Mohler ER, 3rd, Moy CS, Mussolino ME, Neumar RW, Nichol G, Pandey DK, Paynter NP, Reeves MJ, Sorlie PD, Stein J, Towfighi A, Turan TN, Virani SS, Wong ND, Woo D, Turner MB; American Heart Association Statistics Committee and Stroke Statistics Subcommittee: Heart disease and stroke statistics-2014 update: A report from the American Heart Association. Circulation 2014;129:e28-e292.

4. Lakatta EG: So! What's aging? Is cardiovascular aging a disease? J Mol Cell Cardiol 2015;83:1-13.

5. Kovacic JC, Moreno P, Nabel EG, Hachinski V, Fuster V: Cellular senescence, vascular disease, and aging: Part 2 of a 2part review: Clinical vascular disease in the elderly. Circulation 2011;123:1900-1910.

6. Harvey A, Montezano AC, Touyz RM: Vascular biology of ageing-Implications in hypertension. J Mol Cell Cardiol 2015; 83:112-121.

7. Martín-Fernández B, Gredilla R: Mitochondria and oxidative stress in heart aging. Age (Dordr) 2016;38:225-238.

8. Ortega R: Importance of functional foods in the Mediterranean diet. Public Health Nutr 2006;9:1136-1140.

9. Simopoulos AP: The Mediterranean diets: What is so special about the diet of Greece? The scientific evidence. J Nutr 2001; 131:3065S-3073S.

10. Malaguti M, Angeloni C, Hrelia S: Nutraceutical bioactive compounds promote healthspan counteracting cardiovascular diseases. J Am Coll Nutr 2015;34:22-27.

11. Davinelli S, Scapagnini G: Polyphenols: A promising nutritional approach to prevent or reduce the progression of prehypertension. High Blood Press Cardiovasc Prev 2016;23:197-202.

12. Davinelli S, Bertoglio JC, Zarrelli A, Pina R, Scapagnini G: A randomized clinical trial evaluating the efficacy of an anthocyanin-maqui berry extract $\left(\right.$ Delphinol ${ }^{\circledR}$ ) on oxidative stress biomarkers. J Am Coll Nutr 2015;34:28-33.

13. Jumar A, Schmieder RE: Cocoa flavanol cardiovascular effects beyond blood pressure reduction. J Clin Hypertens (Greenwich) 2016;18:352-358.

14. Wiswedel I, Hirsch D, Kropf S, Gruening M, Pfister E, Schewe $\mathrm{T}$, Sies H: Flavanol-rich cocoa drink lowers plasma $\mathrm{F}(2)-$ isoprostane concentrations in humans. Free Radic Biol Med 2004;37:411-421.

15. Miller PE, Van Elswyk M, Alexander DD: Long-chain omega-3 fatty acids eicosapentaenoic acid and docosahexaenoic acid and blood pressure: A meta-analysis of randomized controlled trials. Am J Hypertens 2014;27:885-896.

16. Serhan CN, Chiang N, Van Dyke TE: Resolving inflammation: Dual anti-inflammatory and pro-resolution lipid mediators. Nat Rev Immunol 2008;8:349-361.

17. Andres-Lacueva C, Monagas M, Khan N, Izquierdo-Pulido M, Urpi-Sarda M, Permanyer J, Lamuela-Raventós RM: Flavanol and flavonol contents of cocoa powder products: Influence of the manufacturing process. J Agric Food Chem 2008;56:31113117.

18. Manach C, Scalbert A, Morand C, Rémésy C, Jiménez L: Polyphenols: Food sources and bioavailability. Am J Clin Nutr 2004;79:727-747. 
19. Dai J, Mumper RJ: Plant phenolics: Extraction, analysis and their antioxidant and anticancer properties. Molecules 2010;15: 7313-7352.

20. Kelm MA, Johnson JC, Robbins RJ, Hammerstone JF, Schmitz $\mathrm{HH}$ : High-performance liquid chromatography separation and purification of cacao (Theobroma cacao L.) procyanidins according to degree of polymerization using a diol stationary phase. J Agric Food Chem 2006;54:1571-1576.

21. Kim J, Kim J, Shim J, Lee CY, Lee KW, Lee HJ: Cocoa phytochemicals: Recent advances in molecular mechanisms on health. Crit Rev Food Sci Nutr 2014;54:1458-1472.

22. Corti R, Flammer AJ, Hollenberg NK, Lüscher TF: Cocoa and cardiovascular health. Circulation 2009;119:1433-1441.

23. Bjelakovic G, Nikolova D, Gluud LL, Simonetti RG, Gluud C: Antioxidant supplements for prevention of mortality in healthy participants and patients with various diseases. Cochrane Database Syst Rev 2012;3:CD007176.

24. Ibero-Baraibar I, Abete I, Navas-Carretero S, Massis-Zaid A, Martinez JA, Zulet MA: Oxidised LDL levels decreases after the consumption of ready-to-eat meals supplemented with cocoa extract within a hypocaloric diet. Nutr Metab Cardiovasc Dis 2014;24:416-422.

25. McFarlin BK, Venable AS, Henning AL, Prado EA, Best Sampson JN, Vingren JL, Hill DW: Natural cocoa consumption: Potential to reduce atherogenic factors? J Nutr Biochem 2015; 26:626-632.

26. Kraemer T, Prakosay I, Date RA, Sies H, Schewe T: Oxidative modification of low-density lipoprotein: Lipid peroxidation by myeloperoxidase in the presence of nitrite. Biol Chem 2004; 385:809-818.

27. Sanbongi C, Suzuki N, Sakane T: Polyphenols in chocolate, which have antioxidant activity, modulate immune functions in humans in vitro. Cell Immunol 1997;177:129-136.

28. Cooper KA, Donovan JL, Waterhouse AL, Williamson G: Cocoa and health: A decade of research. Br J Nutr 2008;99:1-11.

29. Dick SA, Epelman S: Chronic heart failure and inflammation: What do we really know? Circ Res 2016;119:159-176.

30. Fontes JA, Rose NR, Čiháková D. The varying faces of IL-6: From cardiac protection to cardiac failure. Cytokine 2015;74:62-68.

31. Mackenzie GG, Carrasquedo F, Delfino JM, Keen CL, Fraga CG, Oteiza PI: Epicatechin, catechin, and dimeric procyanidins inhibit PMA-induced NF-kappaB activation at multiple steps in Jurkat T cells. FASEB J 2004;18:167-169.

32. Mackenzie GG, Oteiza PI: Modulation of transcription factor NF-kappaB in Hodgkin's lymphoma cell lines: Effect of (-)epicatechin. Free Radic Res 2006;40:1086-1094.

33. Hollenberg NK, Martinez G, McCullough M, Meinking T, Passan D, Preston M, Rivera A, Taplin D, Vicaria-Clement M: Aging, acculturation, salt intake, and hypertension in the Kuna of Panama. Hypertension 1997;29:171-176.

34. Mink PJ, Scrafford CG, Barraj LM, Harnack L, Hong CP, Nettleton JA, Jacobs DR, Jr.: Flavonoid intake and cardiovascular disease mortality: A prospective study in postmenopausal women. Am J Clin Nutr 2007;85:895-909.

35. Buijsse B, Weikert C, Drogan D, Bergmann M, Boeing H: Chocolate consumption in relation to blood pressure and risk of cardiovascular disease in German adults. Eur Heart $J$ 2010;31: 1616-1623.

36. Janszky I, Mukamal KJ, Ljung R, Ahnve S, Ahlbom A, Hallqvist J: Chocolate consumption and mortality following a first acute myocardial infarction: The Stockholm Heart Epidemiology Program. J Intern Med 2009;266:248-257.

37. Hooper L, Kroon PA, Rimm EB, Cohn JS, Harvey I, Le Cornu KA, Ryder JJ, Hall WL, Cassidy A: Flavonoids, flavonoid-rich foods, and cardiovascular risk: A meta-analysis of randomized controlled trials. Am J Clin Nutr 2008;88:38-50.

38. Hooper L, Kay C, Abdelhamid A, Kroon PA, Cohn JS, Rimm EB, Cassidy A: Effects of chocolate, cocoa, and flavan-3-ols on cardiovascular health: A systematic review and meta-analysis of randomized trials. Am J Clin Nutr 2012;95:740-751.

39. Tokede OA, Gaziano JM, Djoussé L: Effects of cocoa products/ dark chocolate on serum lipids: A meta-analysis. Eur J Clin Nutr 2011;65:879-886.

40. Ried K, Sullivan T, Fakler P, Frank OR, Stocks NP: Does chocolate reduce blood pressure? A meta-analysis. BMC Med 2010;8:39.

41. Wan Y, Vinson JA, Etherton TD, Proch J, Lazarus SA, KrisEtherton PM: Effects of cocoa powder and dark chocolate on LDL oxidative susceptibility and prostaglandin concentrations in humans. Am J Clin Nutr 2001;74:596-602.

42. Osakabe N, Baba S, Yasuda A, Iwamoto T, Kamiyama M, Takizawa T, Itakura H, Kondo K: Daily cocoa intake reduces the susceptibility of low-density lipoprotein to oxidation as demonstrated in healthy human volunteers. Free Radic Res 2001;34:93-99.

43. Grassi D, Necozione S, Lippi C, Croce G, Valeri L, Pasqualetti P, Desideri G, Blumberg JB, Ferri C: Cocoa reduces blood pressure and insulin resistance and improves endotheliumdependent vasodilation in hypertensives. Hypertension 2005;46: 398-405.

44. Baba S, Osakabe N, Kato Y, Natsume M, Yasuda A, Kido T, Fukuda K, Muto Y, Kondo K: Continuous intake of polyphenolic compounds containing cocoa powder reduces LDL oxidative susceptibility and has beneficial effects on plasma HDLcholesterol concentrations in humans. Am J Clin Nutr 2007;85: 709-717.

45. Mursu J, Voutilainen S, Nurmi T, Rissanen TH, Virtanen JK, Kaikkonen J, Nyyssönen K, Salonen JT: Dark chocolate consumption increases HDL cholesterol concentration and chocolate fatty acids may inhibit lipid peroxidation in healthy humans. Free Radic Biol Med 2004;37:1351-1359.

46. Selvaraj S, Krishnaswamy S, Devashya V, Sethuraman S, Krishnan UM: Influence of membrane lipid composition on flavonoid-membrane interactions: Implications on their biological activity. Prog Lipid Res 2015;58:1-13.

47. Grassi D, Desideri G, Ferri C: Flavonoids: Antioxidants against atherosclerosis. Nutrients 2010;2:889-902.

48. Kris-Etherton PM, Derr J, Mitchell DC, Mustad VA, Russell ME, McDonnell ET, Salabsky D, Pearson TA: The role of fatty acid saturation on plasma lipids, lipoproteins, and apolipoproteins: I. Effects of whole food diets high in cocoa butter, olive oil, soybean oil, dairy butter, and milk chocolate on the plasma lipids of young men. Metabolism 1993;42:121-129.

49. Denke MA: Dietary fats, fatty acids, and their effects on lipoproteins. Curr Atheroscler Rep 2006;8:466-471.

50. Mensink RP, Zock PL, Kester AD, Katan MB: Effects of dietary fatty acids and carbohydrates on the ratio of serum total to HDL cholesterol and on serum lipids and apolipoproteins: A meta-analysis of 60 controlled trials. Am J Clin Nutr 2003;77: 1146-1155. 
51. Lin X, Zhang I, Li A, Manson JE, Sesso HD, Wang L, Liu S: Cocoa flavanol intake and biomarkers for cardiometabolic health: A systematic review and meta-analysis of randomized controlled trials. J Nutr 2016;146:2325-2333.

52. Grassi D, Lippi C, Necozione S, Desideri G, Ferri C: Short-term administration of dark chocolate is followed by a significant increase in insulin sensitivity and a decrease in blood pressure in healthy persons. Am J Clin Nutr 2005;81:611-614.

53. Grassi D, Desideri G, Necozione S, Lippi C, Casale R, Properzi $\mathrm{G}$, Blumberg JB, Ferri C: Blood pressure is reduced and insulin sensitivity increased in glucose-intolerant, hypertensive subjects after 15 days of consuming high-polyphenol dark chocolate. $J$ Nutr 2008;138:1671-1676.

54. Sansone R, Rodriguez-Mateos A, Heuel J, Falk D, Schuler D, Wagstaff R, Kuhnle GG, Spencer JP, Schroeter H, Merx MW, Kelm M, Heiss C; Flaviola Consortium, European Union 7th Framework Program: Cocoa flavanol intake improves endothelial function and Framingham Risk Score in healthy men and women: A randomised, controlled, double-masked trial: The Flaviola Health Study. Br J Nutr 2015;114:1246-1255.

55. Ellinger S, Stehle P: Impact of cocoa consumption on inflammation processes-a critical review of randomized controlled trials. Nutrients 2016;8:E321.

56. Monagas M, Khan N, Andres-Lacueva C, Casas R, Urpí-Sardà M, Llorach R, Lamuela-Raventós RM, Estruch R: Effect of cocoa powder on the modulation of inflammatory biomarkers in patients at high risk of cardiovascular disease. Am J Clin Nutr 2009;90:1144-1150.

57. Pearson DA, Holt RR, Rein D, Paglieroni T, Schmitz HH, Keen CL: Flavanols and platelet reactivity. Clin Dev Immunol 2005; 12:1-9.

58. Rein D, Paglieroni TG, Pearson DA, Wun T, Schmitz HH, Gosselin R, Keen CL: Cocoa and wine polyphenols modulate platelet activation and function. J Nutr 2000;130:2120S-2126S.

59. Ostertag LM, O'Kennedy N, Kroon PA, Duthie GG, de Roos B: Impact of dietary polyphenols on human platelet function-A critical review of controlled dietary intervention studies. Mol Nutr Food Res 2010;54:60-81.

60. Dyerberg J, Bang HO, Hjorne N: Fatty acid composition of the plasma lipids in Greenland Eskimos. Am J Clin Nutr 1975;28: 958-966.

61. Mozaffarian D, Wu JH: Omega-3 fatty acids and cardiovascular disease: Effects on risk factors, molecular pathways, and clinical events. J Am Coll Cardiol 2011;58:2047-2067.

62. von Schacky C: Omega-3 fatty acids and cardiovascular disease. Curr Opin Clin Nutr Metab Care 2004;7:131-136.

63. Bowen KJ, Harris WS, Kris-Etherton PM: Omega-3 fatty acids and cardiovascular disease: Are there benefits? Curr Treat Options Cardiovasc Med 2016;18:69.

64. Bucher HC, Hengstler P, Schindler C, Meier G: N-3 polyunsaturated fatty acids in coronary heart disease: A meta-analysis of randomized controlled trials. Am J Med 2002;112:298-304.

65. Harris WS: Extending the cardiovascular benefits of omega-3 Fatty acids. Curr Atheroscler Rep 2005;7:375-380.

66. Daviglus ML, Stamler J, Orencia AJ, Dyer AR, Liu K, Greenland P, Walsh MK, Morris D, Shekelle RB: Fish consumption and the 30-year risk of fatal myocardial infarction. $N$ Engl J Med 1997;336:1046-1053.

67. Hu FB, Bronner L, Willett WC, Stampfer MJ, Rexrode KM, Albert CM, Hunter D, Manson JE: Fish and omega-3 fatty acid intake and risk of coronary heart disease in women. JAMA 2002;287:1815-1821.

68. He K, Song Y, Daviglus ML, Liu K, Van Horn L, Dyer AR, Greenland P: Accumulated evidence on fish consumption and coronary heart disease mortality: A meta-analysis of cohort studies. Circulation 2004;109:2705-2711.

69. Sala-Vila A, Guasch-Ferré M, Hu FB, Sánchez-Tainta A, Bulló M, Serra-Mir M, López-Sabater C, Sorlí JV, Arós F, Fiol M, Muñoz MA, Serra-Majem L, Martínez JA, Corella D, Fitó M, Salas-Salvadó J, Martínez-González MA, Estruch R, Ros E; PREDIMED Investigators: Dietary $\alpha$-linolenic acid, marine $\omega-3$ fatty acids, and mortality in a population with high fish consumption: Findings from the PREvención con DIeta MEDiterránea (PREDIMED) Study. J Am Heart Assoc 2016;5:pii: e002543.

70. Clark CM, Monahan KD, Drew RC: Omega-3 polyunsaturated fatty acid supplementation attenuates blood pressure increase at onset of isometric handgrip exercise in healthy young and older humans. Physiol Rep 2016;4:e12875.

71. Minihane AM, Armah CK, Miles EA, Madden JM, Clark AB, Caslake MJ, Packard CJ, Kofler BM, Lietz G, Curtis PJ, Mathers JC, Williams CM, Calder PC: Consumption of fish oil providing amounts of eicosapentaenoic acid and docosahexaenoic acid that can be obtained from the diet reduces blood pressure in adults with systolic hypertension: A retrospective analysis. $J$ Nutr 2016;146:516-523.

72. Macartney MJ, Hingley L, Brown MA, Peoples GE, McLennan PL: Intrinsic heart rate recovery after dynamic exercise is improved with an increased omega-3 index in healthy males. $\mathrm{Br} \mathrm{J}$ Nutr 2014;112:1984-1992.

73. Tousoulis D, Plastiras A, Siasos G, Oikonomou E, Verveniotis A, Kokkou E, Maniatis K, Gouliopoulos N, Miliou A, Paraskevopoulos T, Stefanadis C: Omega-3 PUFAs improved endothelial function and arterial stiffness with a parallel antiinflammatory effect in adults with metabolic syndrome. Atherosclerosis 2014;232:10-16.

74. Harris WS, Miller M, Tighe AP, Davidson MH, Schaefer EJ: Omega-3 fatty acids and coronary heart disease risk: Clinical and mechanistic perspectives. Atherosclerosis 2008;197:12-24.

75. Furuhashi M, Hiramitsu S, Mita T, Omori A, Fuseya T, Ishimura S, Watanabe Y, Hoshina K, Matsumoto M, Tanaka M, Moniwa N, Yoshida H, Ishii J, Miura T: Reduction of circulating FABP4 level by treatment with omega-3 fatty acid ethyl esters. Lipids Health Dis 2016;15:5.

76. Cawood AL, Ding R, Napper FL, Young RH, Williams JA, Ward MJ, Gudmundsen O, Vige R, Payne SP, Ye S, Shearman CP, Gallagher PJ, Grimble RF, Calder PC: Eicosapentaenoic acid (EPA) from highly concentrated n-3 fatty acid ethyl esters is incorporated into advanced atherosclerotic plaques and higher plaque EPA is associated with decreased plaque inflammation and increased stability. Atherosclerosis 2010;212:252-259.

77. Eaton SB, Eaton SB, 3rd, Sinclair AJ, Cordain L, Mann NJ: Dietary intake of long-chain polyunsaturated fatty acids during the paleolithic. World Rev Nutr Diet 1998;83:12-23.

78. Simopoulos AP, DiNicolantonio JJ: The importance of a balanced $\omega-6$ to $\omega-3$ ratio in the prevention and management of obesity. Open Heart 2016;3:e00385.

79. Simopoulos AP: The importance of the omega-6/omega-3 fatty acid ratio in cardiovascular disease and other chronic diseases. Exp Biol Med (Maywood) 2008;233:674-688. 
80. Das UN: Essential fatty acids and their metabolites could function as endogenous HMG-CoA reductase and ACE enzyme inhibitors, anti-arrhythmic, anti-hypertensive, antiatherosclerotic, anti-inflammatory, cytoprotective, and cardioprotective molecules. Lipids Health Dis 2008;7:37.

81. Russo GL: Dietary n-6 and n-3 polyunsaturated fatty acids: From biochemistry to clinical implications in cardiovascular prevention. Biochem Pharmacol 2009;77:937-946.

82. Bagga D, Wang L, Farias-Eisner R, Glaspy JA, Reddy ST: Differential effects of prostaglandin derived from omega- 6 and omega-3 polyunsaturated fatty acids on COX-2 expression and IL-6 secretion. Proc Natl Acad Sci U S A 2003;100:1751-1756.

83. Calder PC: $n-3$ polyunsaturated fatty acids, inflammation, and inflammatory diseases. Am J Clin Nutr 2006;83:1505S-1519S.

84. Wanten GJ, Calder PC: Immune modulation by parenteral lipid emulsions. Am J Clin Nutr 2007;85:1171-1184.

85. Calder PC, Grimble RF: Polyunsaturated fatty acids, inflammation and immunity. Eur J Clin Nutr 2002;56:S14-S19.

86. Calder PC: Dietary modification of inflammation with lipids. Proc Nutr Soc 2002;61:345-358.

87. Simopoulos AP: Omega-3 fatty acids in inflammation and autoimmune diseases. J Am Coll Nutr 2002;21:495-505.

88. Homaidan FR, Chakroun I, Haidar HA, El-Sabban ME: Protein regulators of eicosanoid synthesis: Role in inflammation. Curr Protein Pept Sci 2002;3:467-484.

89. Jiang J, Li K, Wang F, Yang B, Fu Y, Zheng J, Li D: Effect of marine-derived n-3 polyunsaturated fatty acids on major eicosanoids: A systematic review and meta-analysis from 18 randomized controlled trials. PLoS One 2016;11:e0147351.

90. Sears B, Ricordi C: Anti-inflammatory nutrition as a pharmacological approach to treat obesity. J Obes 2011;2011:431985.

91. Baylin A, Campos H: Arachidonic acid in adipose tissue is associated with nonfatal acute myocardial infarction in the central valley of Costa Rica. J Nutr 2004;134:3095-3099.

92. Tull SP, Yates CM, Maskrey BH, O'Donnell VB, Madden J, Grimble RF, Calder PC, Nash GB, Rainger GE: Omega-3 Fatty acids and inflammation: Novel interactions reveal a new step in neutrophil recruitment. PLoS Biol 2009; 7:e1000177.

93. Simopoulos AP: An increase in the omega-6/omega-3 fatty acid ratio increases the risk for obesity. Nutrients 2016;8:128.

94. de Lorgeril M, Salen P, Martin JL, Boucher F, de Leiris J: Interactions of wine drinking with omega- 3 fatty acids in patients with coronary heart disease: A fish-like effect of moderate wine drinking. Am Heart J 2008;155:175-181.

95. Schewe T, Sadik C, Klotz LO, Yoshimoto T, Kühn H, Sies H: Polyphenols of cocoa: Inhibition of mammalian 15lipoxygenase. Biol Chem 2001;382:1687-1696.

96. Schewe T, Kühn H, Sies H: Flavonoids of cocoa inhibit recombinant human 5-lipoxygenase. J Nutr 2002;132:1825-1829.

97. Gu Y, Yu S, Park JY, Harvatine K, Lambert JD: Dietary cocoa reduces metabolic endotoxemia and adipose tissue inflammation in high-fat fed mice. J Nutr Biochem 2014;25:439-445.
98. Schramm DD, Wang JF, Holt RR, Ensunsa JL, Gonsalves JL, Lazarus SA, Schmitz HH, German JB, Keen CL: Chocolate procyanidins decrease the leukotriene-prostacyclin ratio in humans and human aortic endothelial cells. Am J Clin Nutr 2001; 73:36-40.

99. Selmi C, Mao TK, Keen CL, Schmitz HH, Eric Gershwin M: The anti-inflammatory properties of cocoa flavanols. J Cardiovasc Pharmacol 2006;47:S163-S167.

100. Kim S, Sohn I, Lee YS, Lee YS: Hepatic gene expression profiles are altered by genistein supplementation in mice with diet-induced obesity. J Nutr 2005;135:33-41.

101. Li RW, Theriault AG, Au K, Douglas TD, Casaschi A, Kurowska EM, Mukherjee R: Citrus polymethoxylated flavones improve lipid and glucose homeostasis and modulate adipocytokines in fructose-induced insulin resistant hamsters. Life Sci 2006;79:365-373.

102. Mezei O, Li Y, Mullen E, Ross-Viola JS, Shay NF: Dietary isoflavone supplementation modulates lipid metabolism via PPARalpha-dependent and -independent mechanisms. Physiol Genomics 2006;26:8-14.

103. Toufektsian MC, Salen P, Laporte F, Tonelli C, de Lorgeril M: Dietary flavonoids increase plasma very long-chain (n-3) fatty acids in rats. $J$ Nutr 2011;141:37-41.

104. Cocoa Supplement and Multivitamin Outcomes Study (COSMOS): ClinicalTrials.gov identifier (NCT number): NCT02422745. https:// clinicaltrials.gov/ct2/show/NCT02422745 (accessed January 2018).

105. Tomé-Carneiro J, Visioli F: Polyphenol-based nutraceuticals for the prevention and treatment of cardiovascular disease: Review of human evidence. Phytomedicine 2016;23:1145-1174.

106. Davinelli S, Sapere N, Visentin M, Zella D, Scapagnini G: Enhancement of mitochondrial biogenesis with polyphenols: Combined effects of resveratrol and equol in human endothelial cells. Immun Ageing 2013;10:28.

107. Genovese C, Davinelli S, Mangano K, Tempera G, Nicolosi D, Corsello S, Vergalito F, Tartaglia E, Scapagnini G, Di Marco R: Effects of a new combination of plant extracts plus d-mannose for the management of uncomplicated recurrent urinary tract infections. J Chemother 2018;30:107-114.

108. Davinelli S, Scapagnini G, Marzatico F, Nobile V, Ferrara N, Corbi G: Influence of equol and resveratrol supplementation on health-related quality of life in menopausal women: A randomized, placebo-controlled study. Maturitas 2017;96:77-83.

109. Davinelli S, Di Marco R, Bracale R, Quattrone A, Zella D, Scapagnini G: Synergistic effect of L-Carnosine and EGCG in the prevention of physiological brain aging. Curr Pharm Des 2013;19:2722-2727.

110. Bozzetto L, Annuzzi G, Pacini G, Costabile G, Vetrani C, Vitale M, Griffo E, Giacco A, De Natale C, Cocozza S, Della Pepa G, Tura A, Riccardi G, Rivellese AA: Polyphenol-rich diets improve glucose metabolism in people at high cardiometabolic risk: A controlled randomised intervention trial. Diabetologia 2015;58:1551-1560. 